\title{
A Educação Financeira Escolar em Portugal
}

\author{
Ana Elisa Esteves Santiago \\ Universidade Nova de Lisboa, Portugal \\ Unidade de Investigação em Educação e Desenvolvimento \\ elisa_santiago@hotmail.com
}

\section{Resumo}

Este artigo tem como objetivo principal descrever a forma como a Educação Financeira está a ser implementada em Portugal. Para tal iremos começar por explicar como e porque surgiu o tema, a nível internacional e, depois, a nível nacional, nomeadamente o trabalho desenvolvido pelo Conselho Nacional de Supervisores Financeiros e o Ministério da Educação e Ciência de Portugal. Identificaremos ainda as várias instituições que desenvolvem iniciativas na área da Educação Financeira Escolar, nomeadamente associações ligadas ao sector financeiro, instituições de crédito, instituições de apoio ao consumidor e instituições de ensino superior. Iremos ainda abordar o modo como estes estão a desenvolver os seus projetos.

Palavras-chave: Educação Financeira. Literacia Financeira. Currículo. Formação.

\section{Scholar Financial Education in Portugal}

\begin{abstract}
This article aims to describe how the Financial Education is being implemented in Portugal. To do this we will start by explaining how and why the subject arose at international level and then at national level, in particular the work of the National Council of Financial Supervisors and the Ministry of Education and Science of Portugal. Also identify the institutions that develop initiatives in the area of Financial Education at School, including associations from the financial sector, credit institutions, consumer support institutions and higher education institutions. We will also discuss how these are developing their projects.
\end{abstract}

Keywords: Financial Education. Financial Literacy. Curriculum. Training.

\section{Introdução}

A Organização para a Cooperação e Desenvolvimento Econômico (OCDE) é uma organização internacional com 34 países membros e que tem como objetivo orientar os países em um grande número de temas como comércio, energia, indicadores econômicos, educação e saúde. Entre os assuntos que entraram em pauta em sua reunião do conselho em 2003 estava um projeto intitulado Projeto de Educação Financeira que tinha como objetivo propor ações para educar financeiramente a população dos países filiados.

Portugal sendo um dos países membros da OCDE tem participado das ações recomedadas pela organização na introdução da Educação Financeira nas escolas portuguesas. 
O projeto de Educação Financeira da organização teve duas fases iniciais. A primeira fase resultou no documento intitulado Improving Financial Literacy: Analysis of Issues and Policies (OECD, 2005a). Ainda no ano de 2005, a organização publicou um segundo documento intitulado Recommendation on Principles and Good Practices For Financial Education and Awareness para orientar os governos em suas ações. Este documento contém sete princípios e quatro linhas de boas práticas relativas à Educação Financeira. Desde então a Educação Financeira faz parte da agenda internacional, mobilizando o G20 ${ }^{1}$, bancos centrais, supervisores financeiros, entre outros.

Na seção "Boas Práticas", do documento, encontramos a recomendação de que a educação Financeira deveria começar na escola, pois, as pessoas deveriam ser educadas sobre questões financeiras o mais cedo possível em suas vidas. (OECD, 2005b). E, como consequência dessa perspectiva, o documento sugeria:

Para os programas que favoreçam o uso de sala de aula, devem ser promovidos cursos adequados e a capacitação dos educadores. Assim, precisam ser incentivados programas de "formação dos formadores", e a distribuição de material informativo específico e ferramentas para estes formadores. (OECD, 2005b, p.7)

O documento trazia ainda duas definições que orientariam os formuladores de políticas em seus estudos. A Educação Financeira foi definida como:

Educação Financeira é o processo pelo qual os consumidores financeiros/ investidores melhoram a sua compreensão sobre os conceitos e produtos financeiros e, através da informação, instrução e/ou aconselhamento objetivos, desenvolvam as habilidades e a confiança para tomar consciência de riscos e oportunidades financeiras, para fazer escolhas informadas, saber onde buscar ajuda e tomar outras medidas eficazes para melhorar a sua proteção e o seu bem-estar financeiro. (OECD, 2005a, p. 26)

A Literacia financeira foi definida como:

Literacia financeira é uma combinação de consciência, conhecimento, habilidade, atitude e comportamento necessários para tomar consistentes decisões financeiras e alcançar almejado bem-estar financeiro individual. (OECD, 2005a)

De um modo geral, os documentos salientavam a importância da Educação Financeira, justificada pelo aumento da complexidade dos produtos financeiros e pelos baixos níveis de literacia financeira da população.

Com a leitura dos documentos da organização surgem então as questões: Por que educar financeiramente a população? Quais as mais-valias de educar financeiramente?

Ora, educar financeiramente permite uma melhor preparação para os riscos da vida moderna, melhor compreensão das vantagens e desvantagens das operações financeiras, tem uma contribuição positiva no bem estar das famílias, maior eficiência do sistema financeiro, maior informação e melhor conhecimento. E ainda, incrementa a capacidade negocial, induz melhor qualidade de serviço e induz aumento da concorrência, potencia opções mais corretas na gestão dos orçamentos familiares e na tomada de riscos financeiros e estimula mais poupança e menor endividamento.

\footnotetext{
${ }^{1}$ Grupo formado pelos ministros de finanças e chefes dos bancos centrais das 19 maiores economias do mundo mais a União Europeia.
} 
Outra questão que se coloca é: quais são os agentes de educação financeira? Assim, envolvidos na Educação Financeira deverão estar o Estado, o Sistema de Ensino, as Instituições Financeiras e Reguladores e ainda as Empresas e famílias.

Assim, considerando a proposição da OCDE do projeto de Educação Financeira, passaremos a analisar as ações desenvolvidas em Portugal de implementação da Educação Financeira nas escolas.

\section{O Conselho Nacional de Supervisores Financeiros}

A par dos movimentos internacionais, também Portugal começou a desenvolver uma estratégia de Educação Financeira. Desde o início de 2008 o Banco de Portugal (BdP) teve a atribuição de competências específicas de supervisão comportamental tendo, desde então, assumido um papel relevante na área da Educação Financeira, em Portugal.

Uma das primeiras iniciativas tomadas pelo Banco de Portugal foi a realização de um inquérito à literacia financeira dos portugueses, em 2010, que teve como objetivo identificar os comportamentos financeiros dos portugueses, medir a inclusão financeira, saber quais os critérios utilizados pelos portugueses na escolha de produtos financeiros e se sabem como estes funcionam, avaliar quais os hábitos de gestão do orçamento e da poupança dos inquiridos e perceber se a população tem conhecimentos sobre conceitos financeiros chave ${ }^{2}$.

Este serviu como instrumento de diagnóstico à definição de uma estratégia nacional de formação financeira, como suporte à preparação de iniciativas de regulação comportamental, como instrumento de avaliação de programas de formação financeira e como apoio à definição de programas de formação financeira.

$\mathrm{O}$ inquérito foi feito sobre a forma de questionário, com 94 perguntas de múltipla escolha, abarcando seis áreas temáticas: inclusão financeira, gestão de conta bancária, planeamento de despesas e poupança, escolha de produtos bancários, escolha e conhecimentos das fontes de informação e compreensão financeira. Foram elaboradas 2000 entrevistas porta-a-porta, em fevereiro e março de 2010, à população com mais de 16 anos. Recorreu-se a uma amostra estratificada com base em cinco critérios (género, idade, localização geográfica, situação laboral e nível de escolaridade).

De uma forma geral, entre os principais resultados destacamos:

- Baixos níveis de conhecimentos financeiros sobre conceitos básicos relevantes para a tomada de decisões financeiras;

- Atitudes em geral adequadas, mas que não se refletem totalmente nos comportamentos financeiros;

- Reduzidos hábitos de poupança;

- Insuficiente compreensão da informação financeira;

- Dificuldades na avaliação e seleção de produtos;

\footnotetext{
${ }^{2}$ Resultados disponíveis em: http://clientebancario.bportugal.pt/ptPT/Publicacoes/InqueritoLiteraciaFinanceira/Biblioteca\%20de\%20Tumbnails/S\%C3\%ADntese\%20dos\%20resultados \%20do\%20Inquérito\%20à\%20Literacia\%20Financeira.pdf
} 
- Grupos populacionais com níveis de literacia financeira distintos: População idosa (com mais de 70 anos) e sem instrução primária, população com menores níveis de escolaridade e de rendimento, população mais jovem e os desempregados.

O passo seguinte foi a criação, em 2011, pelo Conselho Nacional de Supervisores Financeiros ${ }^{3}$, do Plano Nacional de Formação Financeira (PNFF). Este visa contribuir para elevar o nível de conhecimentos financeiros da população e promover a adopção de comportamentos financeiros adequados, através de uma visão integrada de projetos de formação financeira e pela junção de esforços das partes interessadas, concorrendo para aumentar o bem-estar da população e para a estabilidade do sistema financeiro (BdP, CMVM e ISP, 2011, p.3).

Formam definidas as Linhas de Orientação ${ }^{4}$ do PNFF para o período 2011 - 2015. Este documento começa por justificar a importância da formação financeira, passando depois ao diagnóstico de necessidades analisando vários documentos, nomeadamente:

- Inquérito à literacia financeira realizado pelo Banco de Portugal (2010) que, entre outros, permitiu identificar necessidades de literacia financeira em diversas matérias;

- Reclamações e pedidos de informações dos consumidores financeiros que permitiram identificar áreas onde se verificam eventuais lacunas e necessidades de formação financeira;

- Indicadores de endividamento que demostraram existir altos níveis de endividamento da população;

- Indicadores de poupança que demonstraram existir baixos níveis de poupança da população.

Com base nessas informações foram então traçados pelo PNFF cinco objetivos: melhorar conhecimentos e atitudes financeiras; apoiar a inclusão financeira; desenvolver hábitos de poupança; promover o recurso responsável ao crédito e criar hábitos de precaução. (BdP, CMVM e ISP, 2011, p.11).

Os especialistas definiram também cinco áreas de atuação: os estudantes do ensino básico e secundário, estudantes universitários, trabalhadores, grupos vulneráveis e população em geral. (BdP, CMVM e ISP, 2011, p.13).

O PNFF adotou a marca "Todos Contam" onde se encontram agregadas todas as iniciativas do plano que podem ser consultadas no portal www.todoscontam.pt. Este portal disponibiliza conteúdos acerca de finanças pessoais para cada uma das diferentes etapas da vida, possui ainda simuladores, bibliotecas e informação acerca dos eventos, notícias e um boletim informativo.

Atualmente estão envolvidas neste projeto de Educação Financeira em Portugal várias instituições; nomeadamente: o Ministério da Educação e Ciência, as seguradoras, a Associação de Instituições de Crédito Especializado, instituições bancárias, a Associação Portuguesa para a Defesa do Consumidor, a Associação Portuguesa dos Utilizadores e Consumidores de Serviços e Produtos Financeiros, instituições de ensino superior e outras instituições, em particular, instituições de apoio ao consumidor.

\footnotetext{
${ }^{3}$ Formado pelo Banco de Portugal (BdP), Comissão do Mercado de Valores Mobiliários (CMVM) e Instituto de Seguros de Portugal (ISP)

${ }^{4}$ Disponível em:

http://www.cmvm.pt/CMVM/Cooperação\%20Nacional/Conselho\%20Nacional\%20de\%20Supervisores\%20Financeiros /Documents/Plano\%20Nacional\%20de\%20Formação\%20Financeira.pdf
} 


\section{O Referencial de Educação Financeira}

Os estudantes do ensino básico e secundário são uma das áreas de atuação definidas pelo plano, por esse motivo, uma das parcerias foi precisamente com o Ministério da Educação e Ciência (MEC). Tendo sido construído entre as duas entidades, PNFF e MEC, o Referencial de Educação Financeira (REF) publicado em julho de 2013, documento orientador para a implementação da Educação Financeira em contexto educativo e formativo.

Uma das componentes do currículo do ensino pré-universitário é a Educação para a Cidadania, abrangendo estas várias áreas temáticas. Nas suas linhas orientadoras é contemplada a Educação Financeira, referindo que:

A concretização da Educação Financeira permite aos jovens a aquisição de conhecimentos e capacidades fundamentais para as decisões que, no futuro, terão que tomar sobre as suas finanças pessoais, além de se gerar um efeito multiplicador de informação e de formação junto das famílias. (MEC, 2013, p. 5)

Assim sendo, o Referencial de Educação Financeira, é dirigido ao Ensino Pré-escolar, Ensino Básico e Secundário e Educação e Formação de Adultos. Refere que:

Face à pertinência da promoção e implementação da Educação Financeira, e considerando o contexto escolar e formativo de crianças, jovens e adultos, o MEC associou-se ao PNFF, uma iniciativa de 2011 do CNSF, composto pelo BdP, pela CMVM e pelo ISP, que pretende contribuir para elevar o nível de conhecimentos financeiros da população e promover a adoção de comportamentos financeiros adequados, prevendo-se o início da Educação Financeira nas escolas desde a educação pré-escolar até ao ensino superior, com conteúdos adaptados aos vários públicos e níveis de escolaridade. (MEC, 2013, p.6 )

Acrescenta ainda que:

Assim o MEC, representado pela DGE e a ANQEP, em conjunto com o CNSF, elaboraram este Referencial de Educação Financeira (REF), documento orientador para a implementação da Educação Financeira em contexto educativo e formativo. (MEC, 2013, p.6)

Desta forma, do ponto de vista do MEC, a Educação Financeira encontra-se inserida na Educação para a Cidadania (D.L. 139/2012 de 5 de Julho), tem uma dimensão transversal às várias disciplinas, no entanto o referencial não constitui um guia ou programa prescrito, ou seja é um instrumento de apoio que, no âmbito da autonomia de cada estabelecimento de ensino, podem ser utilizados e adaptados em função das opções a definir em cada contexto, enquadrando as práticas a desenvolver. Assim sendo não existe a obrigatoriedade da sua implementação em contexto escolar.

Relativamente à estrutura deste referencial, observa-se que está organizado por níveis de educação e ensino e por ciclos, contém uma metodologia de abordagem específica para cada um destes, identificando os temas globais, integradores de subtemas. Define objetivos por subtema, especificados por descritores de desempenho, sendo que os descritores contemplam um conjunto de conhecimentos, capacidades, atitudes/valores e comportamentos. Abrange seis temas: Planeamento e Gestão do Orçamento, Sistema e Produtos Financeiros Básicos, Poupança, Crédito, Ética e, finalmente, Direitos e Deveres. 
O passo que se seguiu ao lançamento do Referencial de Educação Financeira foi a formação de professores, que teve início em janeiro de 2014 e é ministrada por elementos do Ministério da Educação e Ciência e por elementos do Conselho Nacional de Supervisores Financeiros, na modalidade de Oficina de Formação, integrando sessões presenciais ( 25 horas) e trabalho autónomo ( 25 horas), com vista à aplicação em contexto escolar do Referencial de Educação Financeira. Abrange professores de todos os graus de ensino, desde o pré-escolar até ao Ensino Secundário e de todas as áreas disciplinares e aborda os temas seguintes: gestão do orçamento familiar, o recurso ao crédito, os meios de pagamento, o sistema financeiro, as aplicações de poupança e os deveres do consumidor. A equipa pretende realizar em Portugal Continental cinco oficinas de formação e depois alargar aos dois arquipélagos portugueses: Madeira e Açores. Em janeiro de 2014 iniciou a primeira na região Norte do país, em setembro do mesmo ano iniciou a segunda na região Centro do país e em janeiro de 2015 iniciou a terceira na região de Lisboa e Vale do Tejo. Faltam realizar em Portugal continental duas das oficinas de formação: na região do Alentejo e na região do Algarve e, posteriormente, nos dois arquipélagos.

O MEC e o PNFF pretendem também construir materiais de apoio à implementação em sala de aula. Para tal foi assinado em 19 de dezembro de 2014 um "Protocolo de cooperação para a preparação de materiais didático-pedagógicos de apoio ao Referencial de Educação Financeira", entre o CNSF, o Ministério da Educação e Ciência e associações do setor financeiro (APB ${ }^{5} ; \mathrm{APS}^{6}$; $\mathrm{APFIPP}^{7}$ e $\mathrm{ASFAC}^{8}$ ). Este protocolo tem como objetivo a elaboração, edição e impressão de materiais didático-pedagógicos que apoiem professores e alunos na abordagem aos temas de formação financeira previstos no Referencial de Educação Financeira. Irão começar pelo desenvolvimento de materiais para o $1^{\circ}$ ciclo do Ensino Básico, prevendo-se que estes sejam testados através de uma experiência-piloto a realizar no ano letivo de 2015/2016 com uma amostra de escolas representativa do universo educativo.

\section{Instituições com projetos na área da Educação Financeira}

A Universidade de Aveiro, no âmbito do projeto I\&D PmatE ${ }^{9}$, que tem como missão a aplicação de tecnologias e o desenvolvimento de conteúdos e eventos ao serviço da promoção do sucesso escolar e da cultura científica, sendo um dos seus eixos de intervenção os projetos de intervenção escolar, desenvolveu o projeto Educação + Financeira. Este projeto, em conjunto com a Caixa Geral de Depósitos, visa sensibilizar a população para as questões da Literacia Financeira, tendo para tal desenvolvido alguns materiais e construído uma exposição itinerante, a ser requisitada pelas câmaras municipais de todo o país. Para além deste projeto, organiza, desde 2009, a Conferência Internacional de Educação Financeira (edufin) que contou já com cinco edições. Este evento tem procurado ser um ponto de encontro, de troca de ideias e experiências e de divulgação dos projetos de todos os que em Portugal já estão envolvidos ou querem participar no desenvolvimento das competências, das capacidades e das atitudes das pessoas para enfrentar os problemas e

\footnotetext{
${ }^{5}$ Associação Portuguesa de Bancos

${ }^{6}$ Associação Portuguesa de Seguradores

${ }^{7}$ Associação Portuguesa de Fundos de Investimento

${ }^{8}$ Associação de Instituições de Crédito Especializado

${ }^{9}$ Disponível em: http://pmate4.ua.pt/hexeris/
} 
desafios financeiros do dia a dia, com responsabilidade e autonomia.

A UIED ${ }^{10}$, da Universidade Nova de Lisboa, tem também investigadores envolvidos nesta área. Organizou em julho de 2014 um seminário com o tema Educação Financeira: Um campo de Investigação e formação, onde reuniu professores e investigadores da área da Educação Financeira e contou também com a presença de membros da Direção-Geral da Educação que estão a trabalhar na Educação Financeira. Os investigadores da UIED foram convidados a participar no $1^{\circ}$ Seminário de Pesquisa em Educação Financeira Escolar e Educação Matemática, que decorreu em 2014 na Universidade Federal de Juiz de Fora, Brasil e são os organizadores da $2^{\mathrm{a}}$ edição deste seminário, que irá decorrer em julho de 2015, na Faculdade de Ciências e Tecnologia da Universidade Nova de Lisboa. Esta unidade de investigação centra o seu trabalho na inserção da Educação Financeira nas aulas de Matemática.

Existem também instituições de crédito que desenvolvem, no âmbito da responsabilidade social, iniciativas na área da Educação Financeira.

A Associação Portuguesa de Bancos (APB) desenvolveu o site "Boas práticas, boas contas"", designação adoptada, também, como assinatura de todo o Programa de Literacia Financeira da Banca. Segundo a APB, este visa estimular as pessoas a adoptar boas práticas na gestão dos seus orçamentos familiares de forma a usufruírem de maior estabilidade financeira e, consequentemente, de mais qualidade de vida. Foi criado um Grupo de Trabalho (GT) em 2010, de que fazem parte, para além da APB e do seu Instituto de Formação Bancária (IFB), os Bancos que integram os Órgãos Sociais da Associação. Este grupo tem como objetivo que estas duas instituições, em conjunto com os seus associados, assumam um papel ativo na educação financeira da população e contribuir para uma melhor compreensão do funcionamento e da importância do sistema financeiro na economia do país. Assim sendo, a APB propõe o desenvolvimento de programas de literacia financeira, comuns a toda a banca, organizados por áreas de atuação e abrangendo a totalidade do território nacional, todos grupos etários e todos os grupos socioeconómicos, nomeadamente crianças, jovens e professores.

Outra instituição envolvida na Educação Financeira, já referida anteriormente é a ANSFAC. Para além da formação, em parceria com o grupo editorial Leya tem também no seu sítio na internet muita informação acerca do tema, distribuída pelos seguintes itens: Competências Básicas, Crianças e o Dinheiro, Orçamento Familiar, Tipos de Crédito, Recorrer ao Crédito, Segurança no Crédito, Endividamento e Incumprimento. Tem ainda vocabulário financeiro, testes de conhecimentos, simuladores, vídeos e Newsletters. Estabeleceu também parcerias com órgãos de Administração Local, Escolas e associações de responsabilidade social.

A Associação Mutualista Montepio, dentro da área da responsabilidade social, criou o Programa de Educação e Informação Financeira, desenvolveu um portal de Educação Financeira ${ }^{12}$ que refere ter como missão:

\footnotetext{
${ }^{10}$ Unidade de Investigação em Educação e Desenvolvimento

${ }^{11}$ Disponível em http://www.boaspraticasboascontas.pt/

${ }^{12}$ Disponível em: http://ei.montepio.pt/
} 
Criar condições, ferramentas e estratégias para todos, garantindo o acesso a conteúdos informativos selecionados, didáticos e relevantes, na área da educação financeira, fazendo a ponte com o Mutualismo e com o espírito de entreajuda e permitindo a todos os públicos uma boa gestão do seu dinheiro, agora e no futuro.

A associação está também ligada ao meio escolar através de projetos na área da Educação Financeira.

Este portal engloba informação para cinco áreas: Pessoal, empresarial, solidário, juvenil, educadores, referindo apresentar em cada uma das áreas, conceitos, infografias, calculadoras, questionários, panorama, academia, fórum empresarial e solidário e fichas educativas.

Também a Caixa Geral de Depósitos criou um portal, Saldo Positivo ${ }^{13}$, contendo artigos, acerca do dinheiro, poupar, crédito, trabalho e investimento. Contém ainda ferramentas tais como simuladores, guias práticos, infogramas e questionários. Esta instituição colabora também com a Universidade de Aveiro, apoiando projetos na área da Educação Financeira.

A Associação Portuguesa para a Defesa do Consumidor, DECO, em parceria com a Santa Casa da Misericórdia e o Portal do Consumidor, desenvolveu o portal Gerir e Poupar ${ }^{14}$ onde são apresentados diversos conteúdos na área da Educação Financeira. Este está dividido em duas partes, uma para crianças entre os 6 e os 12 anos e outra para jovens com mais de 12 anos. Criou também o projeto DECOjovem ${ }^{15}$, dirigido às escolas do Ensino Básico e Secundário, alunos e professores enquanto estrutura de apoio, fonte de informação e formação, centro de recursos e um sítio para divulgar os projetos na área da Educação do Consumidor. Desenvolve nas escolas aderentes, do ensino básico, secundário e profissional, sessões informativas que envolvem, entre outros temas, o tema Literacia Financeira e o tema Gerir e Poupar. Em troca a comunidade escolar recebe informação e recursos que permitem desenvolver atividades e projetos na área do consumo. Os professores contam com o apoio técnico e institucional dos especialistas da DECO.

Uma vez que vários destes projetos tem concursos associados, nomeadamente o PNFF, o Milenium e a DECO, vão surgindo nas escolas várias iniciativas na área da Educação Financeira, com o objetivo de apresentar as iniciativas aos concursos. Um dos projetos, Caixa de Crédito ${ }^{16}$, foi desenhado pelo professor Raul Alves e surgiu em setembro de 2010. Tem como referências de fundamentação o Plano Nacional de Formação Financeira (PNFF - 2011-2015) e o Referencial de Educação Financeira (REF). Desenvolve-se no Agrupamento de Escolas de Santa Bárbara - Fânzeres/Gondomar e Agrupamento de Escolas de Campo Valongo. É uma estratégia de educação financeira na infância, articula as orientações e/ou currículo do Préescolar e $1^{\circ} \mathrm{CEB}$. Favorece a aprendizagem da Matemática e do Português, desenvolvendo as expressões e o conhecimento do mundo, educando para a cidadania. Na página do projeto podemos encontrar informação acerca do projeto e de sua implementação, bem como materiais que podem ser adaptados para implementação em contexto de sala de aula.

\footnotetext{
${ }^{13}$ Disponível em http://saldopositivo.cgd.pt/

${ }_{15}^{14}$ Disponível em http://www.gerirepoupar.com/

${ }_{16}^{15}$ Disponível em http://www.decojovem.pt/

${ }^{16}$ Disponível em http://www.caixadecredito.pt/
} 


\section{Entidades envolvidas na formação de professores no âmbito da Educação Financeira}

Para além da formação de professores anteriormente apresentada, ministrada pelo CNSF e pelo MEC, outras entidades estão também envolvidas na formação de professores no âmbito da Educação Financeira.

A Universidade de Aveiro, no projeto já referido anteriormente tem também como área de atuação a formação de professores, tendo por isso desenvolvido, em 2013, um curso de formação para professores do $1^{\circ}$ Ciclo do Ensino Básico: Educação financeira na escolar. Este curso, com a duração de 25 horas, tinha como objetivo sensibilizar, mobilizar e contribuir para capacitar estes profissionais do ensino para a introdução e abordagem das questões financeiras na escola e como fazê-lo.

O grupo editorial Leya, no qual se integram algumas editoras de língua portuguesa, desenvolve também atividades na área do e-learning. Um dos cursos ministrados, em parceria com a ASFAC, é o curso Educação Financeira para Formadores com a duração de 35 horas, dirigido a educadores, pais e todos os que desempenham um papel na educação de crianças e jovens.

\section{Investigação na área da Literacia Financeira}

Nos últimos anos têm sido desenvolvidos, por parte das instituições de ensino superior, alguns estudos na área da Literacia Financeira e de Educação Financeira, no entanto, apenas identificámos duas teses de mestrado na área da Educação Financeira em contexto escolar Iremos agora referi-los e apresentar uma breve síntese.

O primeiro trabalho publicado foi o de Machado (2011) A literacia financeira da população escolar em Portugal: estudo aplicado a alunos do ensino secundário da Região de Lisboa, feito no âmbito do Mestrado no Instituto Superior de Economia e Gestão da Universidade Técnica de Lisboa. O autor pretendeu realizar este estudo através da implementação de um inquérito a alunos do ensino secundário, de forma a analisar sumariamente a sua capacidade para interpretar, ponderar e fazer escolhas financeiras. Refere o autor que: “o questionário foi construído tendo como base o National Financial Capability Study 2009 National Survey Questionnaire (FINRA, 2009), um questionário aplicado durante o ano de 2009 à população adulta dos Estados Unidos". O autor conclui que:

(...) é possível e necessário investir no reforço da educação financeira, sobretudo direcionada para a promoção da literacia financeira nos jovens.

Tal intervenção exige a criação de programas que integrem a educação financeira nos currículos escolares e no dia-a-dia dos jovens, bem como de estratégias para a avaliação do cumprimento dos objectivos traçados e dos resultados obtidos. (MACHADO, 2011, p. 6970)

O outro estudo, feito por Ribeiro (2013) Literacia financeira: estudo aplicado aos alunos do $3^{\circ}$ Ciclo do Ensino Básico e Secundário, no âmbito do Mestrado em Finanças apresentado na Universidade Portucalense Infante D. Henrique. Foi efetuado um questionário que requer conhecimentos básicos sobre finanças a alunos do $3^{\circ}$ ciclo do Ensino Básico e Ensino Secundário. Refere o autor que este estudo se prende “com a consciencialização sobre a necessidade de formação nesta área, porque permite uma melhor 
qualidade de vida às pessoas e um país mais sustentável a nível económico e financeiro". O autor conclui que:

\begin{abstract}
é necessário investir em educação financeira dos jovens, orientada para a promoção da literacia dos cidadãos de forma a possuírem ferramentas que lhes permitam tomar decisões acertadas relacionadas com a gestão do dinheiro, observadas através do conhecimento, compreensão, capacidades e valores em contextos financeiros e de consumo. (RIBEIRO, 2013, p. 117)
\end{abstract}

Para além de trabalhos desenvolvidos no âmbito de teses de mestrado, identificamos ainda um artigo, da autoria de Carvalhal, Tavares e Sequeira (2012) Práticas criativas transversais para o ensino básico, no âmbito do encontro Matemática e Criatividade, apresentam os projetos desenvolvidos pelo PmatE, na Universidade de Aveiro, na área da Educação Financeira.

Existem mais trabalhos de investigação na área da Educação Financeira, no entanto mais direcionados para estudos com alunos que frequentam o ensino superior. Esses trabalhos têm sido desenvolvidos por instituições da área da Economia e Finanças.

\title{
Considerações Finais
}

Constatamos então que Portugal tem já um grande percurso percorrido, acompanhando as correntes internacionais, no âmbito da Promoção da Educação Financeira. No entanto, verificamos que a formação de professores abrange um número muito limitado de docentes, uma vez que em cada uma das duas regiões por onde já passou a oficina de formação ministrada pelo MEC e pelo PNFF apenas 40 docentes em cada uma delas tiveram oportunidade de a frequentar.

Verificámos também que os materiais didáticos para utilização em sala de aula são ainda muito escassos e não são específicos para cada uma das áreas disciplinares, dificultando a seleção por parte de docente bem como a respectiva implementação.

Apurámos ainda que as investigações desenvolvidas e, até ao momento, publicadas, utilizam uma metodologia de investigação quantitativa, com base em questionários.

Assim sendo, consideramos que seria pertinente num futuro próximo as instituições, nomeadamente as instituições de ensino superior ligadas à formação de professores, desenvolverem projetos que apoiem os professores na inserção das temáticas abrangidas pelo Referencial de Educação Financeira, de uma forma mais específica, para cada disciplina e para cada nível de ensino, nomeadamente na disciplina de Matemática.

\section{Referências}

BdP ( Departamento de Supervisão Bancária). Inquérito à Literacia Financeira da População Portuguesa 2010. 2012, Lisboa, 2012. Disponível em: http://clientebancario.bportugal.pt/ptPT/Publicacoes/InqueritoLiteraciaFinanceira/Biblioteca\%20de\%20Tumbnails/S\%C3\%ADntese\%2 0dos\%20resultados\%20do\%20Inquérito\%20à\%20Literacia\%20Financeira.pdf. Acesso em: 20 de março de 2015. 
BdP, CMVM e ISP. Plano Nacional de Formação Financeira 2011-2015: Linhas de orientação. 2011. Lisboa, 2011. Disponível em:

http://www.cmvm.pt/CMVM/Cooperação\%20Nacional/Conselho\%20Nacional\%20de\%20Supervis ores\%20Financeiros/Documents/Plano\%20Nacional\%20de\%20Formação\%20Financeira.pdf .

Acesso em: 20 de março de 2015

Carvalhal, Ana; Tavares, Catarina; Sequeira, Sandra. Práticas criativas transversais para o ensino básico. In Indagatio Didactica, [S.1.], v. 4, n. 1, Jun. 2012. ISSN 1647-3582. Disponível em: http://revistas.ua.pt/index.php/ID/article/view/1367.

Acesso em: 20 de Março de 2015.

Machado, H. A. M. A literacia financeira da população escolar em Portugal: estudo aplicado a alunos do ensino secundário da Região de Lisboa, 2011. Dissertação de Mestrado. Instituto Superior de Economia e Gestão da Universidade Técnica de Lisboa, Lisboa, 2011.

MEC. Referencial de Educação Financeira, 2013. Lisboa, 2013. Disponível em http://www.dgidc.min-

edu.pt/educacaocidadania/data/educacaocidadania/educacao_financeira/Documentos/referencial_de _educacao_financeira_final_versao_port.pdf. Acesso em: 20 de março de 2015.

OECD. Improving Financial Literacy: Analysis of Issues and Policies. OECD, 2005a.

Disponível em: http://www.browse.oecdbookshop.org/oecd/pdfs/product/2105101e.pdf. Acesso em: 20 de março de 2015.

OECD. Recommendation on Principles and Good Practices for Financial Education and Awareness. Directorate for Financial and Enterprise Affairs. Jul. 2005b. Disponível em: http://www.oecd.org/finance/financial-education/35108560.pdf . Acesso em: 20 de março de 2015.

Ribeiro, E.M.C. Literacia financeira: estudo aplicado aos alunos do $3^{\circ}$ Ciclo do Ensino Básico e Secundário. 2013. Dissertação de Mestrado em Finanças apresentada na Universidade Portucalense Infante D. Henrique, Porto, 2013. 